\title{
LA ACCIÓN SUBROGATORIA DEL ASEGURADOR EN EL TRANSPORTE MARÍTIMO DE MERCADERÍAS*
}

\author{
INSURER SUBROGATION CLAIM \\ IN MARITIME TRANSPORT OF GOODS
}

\author{
FELIPE TABARES CORTÉS $S^{* *}$ \\ Fecha de recepción: 31 de mayo de 2021 \\ Fecha de aceptación: 15 de junio de 2021 \\ Disponible en línea: 30 de junio de 2021
}

Para citar este artículo/To cite this article

TABARES CORTÉs, Felipe. La acción subrogatoria del asegurador en el transporte marítimo de mercaderías, 54 Rev.Ibero-Latinoam.Seguros, 207-226 (2021).

https://doi.org/10.11144/Javeriana.ris54.asat

doi:10.11144/Javeriana.ris54.asat

\footnotetext{
* Reseña crítica y doctrinal sobre una Sentencia reciente de la Corte Suprema de Justicia referente a la acción subrogatoria del asegurador en el transporte marítimo de mercaderías (Corte Suprema de Justicia, Sala Civil, Sentencia de 5 de abril de 2021, Exp. SC1043-2021, MP. Luis Armando Tolosa Villabona).

** Abogado de la barra de Paris y de Colombia. Estudiante de Doctorado en Derecho Público, Université Paris III Sorbonne. Especialista en Derecho Médico de la Universidad del Rosario, Maestría en Derecho de Seguros de la Université Lyon III Jean Moulin, Curso de Preparación del Centro Regional de Formación de Abogados de la Université Paris II PanthéonAssas, Summer Academy on International Investment Law and Disputes Settlement, Kuala Lumpur Regional Centre for Arbitration, Malasia. Contacto: felipetaba@ gmail.com www. fr.linkedin.com/in/ felipetabarescortes
} 


\section{RESUMEN}

En la economía global la regulación del transporte marítimo tiene gran importancia teniendo en cuenta su antigüedad, su volumen y las distancias que actualmente recorren mercancías y materias. En sentencia de 5 de abril de 2021, la Corte Suprema de Justicia de Colombia se refirió a este tema, definiendo el termino de prescripción de la acción subrogatoria del asegurador en el transporte marítimo de mercaderías, específicamente en la avería gruesa. La Corte indicó cuales son las acciones propias del instituto de la avería gruesa y su distinción con el contrato de transporte marítimo de mercaderías. En este articulo recordamos la noción de la avería gruesa, su régimen jurídico y los elementos característicos de esta institución milenaria del derecho marítimo, en derecho colombiano y en derecho comparado francés.

Palabras clave: prescripción de la acción, subrogación, avería gruesa, transporte marítimo, derecho comparado.

\section{ABSTRACT}

In the global economy, the regulation of maritime transport is of great importance if we consider its history, its volume, and the distances that goods and materials travel currently. In a ruling of 5 April 2021, the Colombian Supreme Court of Justice addressed this issue, defining the limitation period of the insurer's subrogation claim in the maritime transport of goods, specifically in the case of general average. The Court stated which are the existing actions in the general average in distinction of the contract of transport of goods by sea. In this article we recall the notions of general average, its legal regime, and the characteristic elements of this millenary institution of maritime law, in Colombian law and in French comparative law.

Key words: limitation period, subrogation, general average, maritime transport, comparative law. 


\begin{abstract}
SUMARIO
Introducción. I. Regímenes de indemnización en el transporte marítimo de mercancías. A. La Responsabilidad Civil en el Transporte Marítimo de Mercancías. 1. El Objeto del Contrato de Transporte Marítimo de Mercancías. 2. La Tipificación de la Obligación del Transportador Marítimo. 3. El Régimen jurídico de la Responsabilidad del Transportador Marítimo de Mercancías. B. La Avería Gruesa como una especie del Incidente Marítimo Mayor. 1. La noción de Avería Gruesa. 2. Obligaciones que surgen tras la declaración de la Avería Gruesa. a. La contribución a la reparación en la Avería Gruesa. b. El procedimiento de compensación en la Avería Gruesa. C. Distinción entre el Régimen de Responsabilidad Contractual y el Régimen Jurídico de la Avería Gruesa como un Incidente Marítimo Mayor. 1. El Evento Desencadenante de la Obligación Contributiva en la Avería Gruesa. 2. El tipo de expensas que configuran la obligación contributiva en la Avería Gruesa. II. La acción subrogatoria del asegurador en la avería gruesa. A. La Acción del Asegurador Subrogado. 1. El Fundamento Jurídico de la Acción del Asegurador Subrogado - El principio de identidad. 2. Condiciones de la Acción del Asegurador Subrogado. B. Límites Temporales de la Acción Subrogatoria del asegurador en la Avería Gruesa. 1. La determinación del Régimen de la Acción Subrogatoria del Asegurador. 2. El Régimen de Prescripción aplicable al Asegurador Subrogado. C. Importancia de la Avería Gruesa como un modo singular de asunción de riesgos. Bibliografía.
\end{abstract}

\title{
INTRODUCCIÓN
}

La ciudad de Bremen perteneció durante muchos siglos a la Liga Hanseática, que fue una organización creada durante la edad media por los grandes puertos marítimos del mar báltico. Un buque portacontenedores de 146 metros de eslora, llamado el "Stadt Bremen", sufrió un siniestro en el año 2010 en aguas colombianas lo que originó un litigio de varios años delante de los jueces de nuestro país. Varias sociedades habían contratado los servicios del armador del buque con el objetivo de transportar mercancías por un valor total de USD $\$ 4.450 .721,43$ hasta la ciudad de Barranquilla. Sin embargo, el 18 de noviembre de 2010, el buque encalló y sufrió varadura al ingresar al puerto. Acaecido el siniestro, el armador declaró la avería gruesa y procedió a procurar las operaciones de salvamento con una sociedad especializada en este tipo de operaciones. En sentencia de 5 de abril de 2021, la Corte Suprema de Justicia de Colombia falló definitivamente el recurso de casación incoado por las aseguradoras, y fue la ocasión para la Sala Civil de definir el tema de la responsabilidad civil marítima y de las cargas que surgen luego del siniestro sufrido por la embarcación Stadt Bremen en el mar caribe colombiano. De esta manera la Corte consagró la regla a aplicar respecto del funcionamiento de las garantías de seguro en derecho marítimo en lo que respecta a la avería gruesa. Por ello, antes de indagar sobre el tema de la acción subrogatoria del asegurador en la avería gruesa (II), nos dispondremos a esbozar los regímenes de indemnización en el transporte marítimo de mercancías (I). 


\section{REGÍMENES DE INDEMNIZACIÓN EN EL TRANSPORTE MARÍTIMO DE MERCANCÍAS}

La aventura marítima exige la previsión de multitud de riesgos frente a montos muy importantes que son en juego en la ejecución de cada contrato de transporte. Es por ello por lo que el derecho marítimo ha regulado de manera diferente cada situación que puede generar efectos jurídicos para las partes al negocio. El tema del régimen jurídico de responsabilidad tiene incidencia directa en la aplicación y funcionamiento de las garantías de seguro. Así, frente a la multiplicidad de regímenes propios de este tipo de transporte y con el objetivo de decantar el principio pretoriano establecido en la sentencia de la Corte Suprema de Justicia comentada, en este artículo nos concentraremos en los elementos de la responsabilidad civil en el transporte marítimo de mercancías (A) y en los elementos propios del régimen jurídico aplicable a los incidentes marítimos mayores, particularmente al de la avería gruesa (B). Finalizaremos esta Sección describiendo los criterios establecidos por la jurisprudencia para distinguir entre ambos regímenes $(C)$.

\section{A. La Responsabilidad Civil en el Transporte Maritimo de Mercancias}

Se considera que el transporte marítimo es el eslabón fundamental del funcionamiento de la economía global, teniendo en cuenta que una gran cantidad de mercancías no pueden ser transportadas por vía aérea o terreaste. El transporte marítimo concentra más del 80\% del volumen del comercio internacional y transporta más del $70 \%$ de su valor (UNCTAD, 2018), siendo para Latinoamérica la vía a través de la cual se exporta más del 60\% de los productos del continente (CEPAL, 2019). Puesto que el principal instrumento regulatorio del transporte marítimo es el contrato, debemos recordar en primera medida cuál es el objeto de este negocio jurídico (1) no sin dejar de mencionar la calificación jurídica propia que le es dada a las obligaciones del transportador marítimo de mercancías (2). Para finalizar esta Sección debemos indicar cuál es el régimen de la responsabilidad civil del transportador marítimo (3).

\section{El Objeto del Contrato de Transporte Maritimo de Mercancias}

En el Contrato de Trasporte Marítimo, a partir del pago de un monto determinado por el remitente, denominado flete, el transportador se compromete a conducir por vía de embarcaciones marítimas y en un plazo fijado, ciertas cosas o mercancías. Este contrato está consagrado en los artículos 1597, 1578, 931, y 1008 Código de Comercio Colombiano. Las obligaciones del transportador nacen cuando el remitente entrega las mercancías y los documentos pertinentes al transportador (artículos 982, 1599, 1605 y 1606 Código de Comercio). Este contrato asume generalmente las formas de conocimiento de embarque, fletamento por viaje (charter party), tiempo (time charter) y casco desnudo (artículos 1666 y 1677 Código de Comercio). Sin 
embargo, en el ordenamiento jurídico colombiano este tipo de negocio puede tomar otras formas jurídicas no consagradas en nuestros códigos ${ }^{1}$.

El contrato de transporte es un contrato comercial, ya que constituye un acto comercial por naturaleza: el transporte. Como a cualquier contrato, a este tipo de acuerdos se le aplican los principios del derecho de las obligaciones regulados por el Código Civil: es el caso de las normas sobre las condiciones de validez (consentimiento, capacidad, objeto, causa), efecto, extinción y prueba de las obligaciones (LANDEL, 2014).

Aún si el concepto de objeto contractual comienza a ser subsumido dentro la noción de causa en algunas legislaciones de países industrializados (Tabares Cortés, 2017), la Corte Suprema colombiana, en la jurisprudencia estudiada §3.4.3.8. (Sentencia SC1043-2021, Sala Civil, 5 abril 2021 MP. Luis Armando Tolosa Villabona, 2021) menciona que la obligación de transporte reviste un carácter complejo, pues envuelve distintas prestaciones, específicamente: i) el traslado de las mercancías de un lugar a otro en las mismas condiciones en que fueron dispuestas por el cargador y en el plazo prefijado, o en ausencia de pacto, en el estimado razonable; ii) la custodia y la conservación de esos efectos comerciales; iii) la entrega de las mercaderías en el puerto de destino y iv) la garantía de navegabilidad de la embarcación. Sin embargo, la Corte Suprema recuerda (\$3.4.3.8.) que, en ausencia de violación de este conjunto de deberes, no tiene lugar el incumplimiento del convenio y que, por ende, no se genera la responsabilidad contractual del armador, situación que tiene consecuencias en el caso objeto de estudio lo cual será explicado ulteriormente.

\section{La Tipificación de la Obligación del Transportador Maritimo}

Las obligaciones del transportador nacen en el momento en el cuál éste recibe las mercancías del remitente y cuando se concreta la obligación asumida de conducir sanas y salvas las cosas hasta su entrega debida (al destinatario, empresa estibadora, descargador o aduana del puerto) haciéndose responsable "de la pérdida total o parcial de la cosa transportada, de su avería y del retardo en la entrega, desde el momento en que ella quede a su disposición", como lo indicó la Sala Civil de la Corte Suprema de Justicia ${ }^{2}$. En el ordenamiento jurídico colombiano, según lo especifica la Corte §3.4.3.6. (Sentencia SC1043-2021, Sala Civil, 5 abril 2021 MP. Luis Armando Tolosa Villabona, 2021), se presume que la inejecución o ejecución defectuosa del contrato es originada en un proceder o una en omisión culposa de quien explota económicamente la actividad comercial. Así, la exoneración del transportador puede ser invocada únicamente en los eventos de culpas náuticas (del capitán, práctico o personal de navegación); incendio; peligros, daños o accidentes de mar o de aguas navegables; fuerza mayor; cuarentenas, huelgas, paros o trabas impuestas al trabajo por cualquier causa; disminución de volumen o peso y de otra pérdida o daño que resulte de la naturaleza especial de la cosa, o de un vicio oculto de la nave; y,

1 CSJ SC 8 sep. 2011, rad. 2000-04366.

2 Sentencias CSJ SC225-1988, 24 jun. 1988; CSJ SC 30 nov. 2004, rad. 0324 y CSJ SC 8 sep. 2011, rad. 2000-04366. 
embalaje insuficiente, deficiencia o imperfección de las marcas (artículo 1609 del Código de Comercio) ${ }^{3}$. Es por ello por lo que nuestra Corte Suprema ha concluido 4 que la obligación del transportador marítimo no es de medios sino, como es establecido en una jurisprudencia de principio $^{5}$, que se trata de una obligación de resultados, puesto que la simple diligencia del prestador no lo exonera de responsabilidad. Esta es la misma regla que se aplica en derecho francés siguiendo a lo establecido en el artículo L. 1411-1 del Código de Transportes. Sin embargo, a pesar de que una circunstancia exoneratoria tenga lugar, el reclamante podrá, según el caso, demostrar que el daño se produjo como resultado de una culpa del transportador, ya que la presunción del articulo L. 1411-1 del Código de Transportes admite prueba en contrario (LANDEL, 2014).

Cuando ninguna de las circunstancias exoneratorias tuvo lugar y la responsabilidad del transportador ha sido demostrada, en aplicación de los textos internacionales y del derecho nacional (artículos 1643 y 1644 del Código de Comercio), una limitación económica de la reparación tiene lugar (instituida por vía legal), lo cual explica que se trate de un régimen especial y exceptivo a las reglas clásicas de la responsabilidad civil y de los seguros terrestres.

\section{El Régimen jurídico de la Responsabilidad del Transportador Maritimo de Mercancias}

El tema de la responsabilidad jurídica del transportador marítimo de mercancías tiene desarrollo tanto legal (i) como jurisprudencial (ii).

i. El Código de Comercio colombiano distinguió, como en otras legislaciones occidentales, por un lado, cual es el régimen que es propio al transporte marítimo, y de otro lado, cual es el régimen jurídico del transporte terrestre. Se trata de dos cuerpos normativos diferentes pero que pueden ser usados por el juzgador bajo ciertos supuestos en ambos regímenes. En efecto, respecto de las disposiciones generales del contrato de transporte terrestre se establece que los artículos 986 y 987 de nuestro Código de Comercio, pueden aplicarse al transporte marítimo por vía únicamente de remisión expresa del legislador, como se establece en el artículo 1646 del mismo Código. Sin embargo, según el artículo 999, en caso de vacíos o lagunas respecto de lo que no está previsto expresamente en el régimen jurídico especial, el corpus normativo general puede aplicarse en los conflictos marítimos si dicha norma no pugna con éste.

Nuestro Código de Comercio regula el tema de la responsabilidad del transportador en su artículo 1030, en su redacción posterior al Decreto extraordinario 01 de enero 2 de 1990, que buscaba otorgar un tratamiento igualitario al tema de la responsabilidad en todos los contratos de transporte. El legislador estableció entonces que el transportador responderá de la pérdida total o parcial de la cosa transportada, de su avería y del retardo en la entrega, desde el momento en que éste la recibe o ha debido hacerse cargo de ella.

\footnotetext{
3 En el mismo sentido la Corte cita la jurisprudencia CSJ SC218, 12 jun. 1990.

4 CSJ SC225, 24 jun. 1988; CSJ SC 26 jun. 2003, rad. 5906; CSJ SC $1^{\circ}$ jun. 2005, rad. 00666; CSJ SC 16 dic. 2010, rad. 00012; CSJ SC 1 jul. 2012, rad. 00055, CSJ SC13594, 6 oct. 2015, rad. -00105.

${ }^{5}$ CSJ SC $1^{\circ}$ jun. 2005, rad. 00666.
} 
Esta responsabilidad solo cesará cuando la cosa sea entregada al destinatario o a la persona designada para recibirla, en el sitio convenido. Esta disposición referente al "transporte de cosas" contenidas en el Capítulo III del Título IV del Código de Comercio, delimita el ámbito temporal de la responsabilidad del porteador, es decir define a partir de qué momento y hasta cuando responde contractualmente por los daños que sufran las mercancías, y señala además las hipótesis en las cuales la responsabilidad puede ser atribuida. Frente al transporte marítimo el artículo 1606 del Código de Comercio se ocupa de fijar sus momentos inicial y final, al preceptuar que ésta comenzará cuando se reciban las cosas o se asuma su custodia, y que terminará con la entrega al destinatario.

ii. El tema del derecho aplicable a la responsabilidad del transportador marítimo ha sido objeto de desarrollo jurisprudencial en Colombia. Nuestra Corte ha confirmado en efecto que el convenio de porte marítimo está dotado de un sistema jurídico particular y autónomo, al cual debe remitirse para la determinación de los derechos y obligaciones de las partes, lo cual tendrá también incidencia en el funcionamiento de las garantías de seguro. La Corte explica que la responsabilidad del transportador está sujeta al régimen jurídico singular, especial y prevalente consignado en los artículos 1578 a 1584 (normas generales), 1585 a 1596 (transporte de personas) y 1597 a 1665 (transporte de mercancías) del Código de Comercio.

Sin embargo, aclara la Sala Civil, el contrato de transporte marítimo de mercancías tiene una regulación normativa independiente y de aplicación preferente frente a las normas del transporte en general ${ }^{6}$. Tratándose de la subespecie de negocios bajo conocimiento de embarque, recuerda la Corte \$3.5.2.1.1. (Sentencia SC1043-2021, Sala Civil, 5 abril 2021 MP. Luis Armando Tolosa Villabona, 2021) que las normas especiales gozan de preeminencia como bien lo señala el artículo 1008 del Código de Comercio, de manera que la integración normativa, si es necesaria, debe satisfacerse primeramente con las reglas del "transporte de cosas por mar", según lo previsto en el artículo 1650 del mismo Código.

La Corte ( $\$ 3$ 3 5 2.1.2. de la misma providencia) va aún más allá puesto que en lo concerniente a la responsabilidad del transportador náutico indica que el régimen marítimo es autónomo lo que limita las potestades del juzgador en la determinación de la norma aplicable, debido a que el artículo 1606 del Código de Comercio regula la cuestión sin que existan lagunas o vacíos. La Sala Civil excluye pues la aplicación, en los litigios relativos a la responsabilidad marítima, del artículo 1030 de nuestro Código de Comercio que debe ceder ante la regla especial.

Se concluye que el Contrato de Transporte Marítimo es una forma de gestionar una parte de los riesgos marítimos que recaen sobre las mercancías y materias transportadas, sin embargo, otros eventos necesitan un tratamiento jurídico diferenciado, específicamente aquellos referidos a los incidentes marítimos mayores.

6 CSJ SC 8 sep. 2011, rad. 2000-04366-01. 


\section{B. LA AVERÍA GRUESA COMO UNA ESPECIE DEL INCIDENTE MARÍTIMO MAYOR}

Los incidentes marítimos son acontecimientos excepcionales que tienen lugar durante la navegación marítima y que están sujetos a una normativa especial (LANDEL, 2014). Los principales siniestros mencionados por la doctrina y los instrumentos internacionales son el abordaje, el salvamento y la avería gruesa. La originalidad del derecho marítimo proviene de las relaciones jurídicas particulares que surgen de estos incidentes marítimos. El debate jurídico subyacente a la Sentencia del 5 abril de 2021 es referido únicamente a la avería gruesa. Por ello, para dar cuenta de este Incidente Marítimo Mayor es conveniente mencionar en primer lugar cuál su noción actual (1) para luego indicar cuales son las obligaciones que surgen una vez ésta es declarada (2).

\section{La noción de Avería Gruesa}

En el derecho marítimo, la avería se define como el daño a los bienes expuestos a los riesgos de la navegación marítima (Montas, 2017). La institución es muy antigua pues desde la lex rhodia ${ }^{7}$ se menciona que el propietario de las mercancías arrojadas por la borda para salvar el buque de peligro debe ser indemnizado por el armador y los propietarios de las mercancías. En derecho romano se consideraba que el buque y la carga conforman un unum germen, pues sus propietarios se encuentran unidos en el común interés de resistir los riesgos de la navegación marítima (Montas, 2017). El fundamento del instituto de la avería reside en una comunión de intereses expuestos a un peligro común: como el sacrificio ha sido decidido por el capitán en interés de todos, sus consecuencias económicas serán asumidas por todos. En realidad, lo común no es el daño, sino su asunción por parte de todos los intereses implicados en la expedición (Montas, 2017). Se entiende por avería gruesa la perdida de una parte de la embarcación marítima (navío y mercancías), pérdida que tiene lugar intencionalmente con el fin de evitar el naufragio (LANDEL, 2014). Así, ocurrida la avería gruesa, los propietarios de los bienes sacrificados reciben una compensación por parte de los propietarios de los bienes salvados. El fundamento jurídico de esta compensación, como lo entiende nuestra Corte Suprema \$3.4.5.4. (Sentencia SC1043-2021, Sala Civil, 5 abril 2021 MP. Luis Armando Tolosa Villabona, 2021), es que los gastos y daños ocasionados en pro del beneficio y utilidad de la expedición náutica, deben distribuirse solidariamente, ya que se incurrió en ellos para la salvaguarda de la empresa común.

Siguiendo la traducción jurídica clásica, el legislador establece una distinción entre la avería gruesa o común y la avería particular. La utilidad de esta distinción es validada por la doctrina desde un punto de vista económico. En efecto, entre las dos categorías de averías no existe una diferencia de naturaleza, en realidad la avería gruesa o común y la avería particular son dos aspectos de la misma cuestión, la diferencia entre ellas se refiere principalmente a las modalidades de indemnización. En la avería particular el daño o gasto debe ser soportado por la persona que lo ha sufrido. En el caso de la avería gruesa,

\footnotetext{
7 Según Montas la ley rodiana (lex rhodia) es el conjunto de leyes y costumbres marítimas más antiguo de la antigua Grecia (475 a.C.).
} 
la reparación o el gasto corre a cargo de todos los interesados en la aventura náutica (MONTAS, 2017).

En derecho colombiano la avería gruesa tiene lugar, según el artículo 1517 del Código de Comercio, cuando intencional y razonablemente se hace un sacrificio extraordinario o se incurre en un gasto para la seguridad común de la embarcación. El objetivo del sacrificio o del gasto deber ser el de preservar del peligro los bienes comprometidos en la navegación. Además, según el artículo 1514 del mismo estatuto, se entiende que todos los daños que sufra la embarcación durante la navegación o en puerto, o las mercancías desde el embarque hasta su desembarque, y todos los gastos extraordinarios e imprevistos que deban efectuarse en beneficio de la nave o de la carga, hacen parte de la avería común.

La Sala Civil no dudó en caracterizar la institución de la avería gruesa. La Corte menciona \$3.4.5.5. (Sentencia SC1043-2021, Sala Civil, 5 abril 2021 MP. Luis Armando Tolosa Villabona, 2021) cinco criterios para identificar su ocurrencia. Primero, tanto los menoscabos (avería-daño) como los desembolsos (avería-gasto), deben ser producto de un acto discrecional y reflexivo del capitán. Segundo, el gasto o sacrificio debe ser razonable, teniendo en cuenta la situación de peligro y la necesidad de adoptar medidas urgentes en el momento de declarar la avería. Tercero, debe ser una situación excepcional, y no de aquellas en que el transportador toma decisiones en cumplimiento de las obligaciones contraídas por virtud del contrato de transporte. Cuatro, debe tratarse de un peligro grave, es decir real, actual, común y evitable. Quinto, el objetivo perseguido debe ser la seguridad común de los participantes en la travesía náutica. Y sexto, los intereses implicados son aquellos de los titulares del buque, la carga y el flete, los cuales están unidos en la situación de riesgo. La jurisprudencia de la Cour de cassation francesa ${ }^{8}$ incluye los mismos criterios, pero precisa uno adicional: al menos en parte, el acto del capitán debe tener un resultado útil en el salvamento de la embarcación.

\section{Obligaciones que surgen tras la declaración de la Averia Gruesa}

Tras la declaración de la avería gruesa se configura en una obligación de contribuir a la reparación del siniestro (a). La Corte menciona cuál es el procedimiento específico para realizar el pago (b).

\section{a. La contribución a la reparación en la Avería Gruesa}

Como ha sido mencionado, la avería gruesa exige la contribución de los propietarios de las mercancías que han sido salvadas del riesgo marítimo. Dicha carga está establecida en derecho interno en el artículo 1518 del Código de Comercio, según el cual los sacrificios y gastos de la avería gruesa estarán a cargo de los diversos intereses llamados a contribuir. La Sala Civil consideró a este respecto §3.4.5.7. (Sentencia SC1043-2021, Sala Civil, 5 abril 2021 MP. Luis Armando Tolosa Villabona, 2021) que, tratándose de gastos extraordinarios realizados con el fin de preservar el buque y la carga

${ }^{8}$ Com. 29 mai 2001, n. 99-10.752. 
de un peligro común, como aquellos en que se incurrió para poner a flote el buque Stadt Bremen después de su encallamiento, éstos deben ser distribuidos a prorrata entre los intereses participantes en la navegación, de tal manera que las partes afectadas sean compensadas por todos, con una contribución proporcional de los propietarios de los bienes salvados.

Por cierto, el legislador colombiano impuso en el artículo 1520 del mismo Código que la obligación de contribuir a la avería subsiste aún si el suceso que le dio origen surja de la culpa de una de las partes interesadas en la navegación, sin perjuicio de las acciones que puedan ejercitarse contra ella. El origen del siniestro no es entonces tenido en cuenta respecto de la obligación de contribución que surge de la avería común, como lo precisa la Corte en la misma Sentencia (§3.5.2.3.1.), puesto que con independencia de que el suceso que dio génesis a la necesidad del sacrificio extraordinario fuera atribuible al obrar culposo de alguno de los interesados, la obligación de contribuir a la reparación incumbe a todos. Por ello la Sala §3.5.2.3. no admitió los argumentos de la censura que pretendían que el régimen de responsabilidad del transportador debía ser aplicado de forma preferente con el fin de atribuir la carga de resarcimiento en cabeza del capital del navío. La Corte aclara sin embargo que la institución de la avería gruesa, en aplicación el artículo 1520 del Código de Comercio, admite una acción de repetición en contra de la persona culpable del siniestro.

\section{b. El procedimiento de compensación en la Averia Gruesa}

En la misma Sentencia de 5 de abril de 2021 la Sala Civil recuerda $\S 3.4 .5 .8$. que, con base en los cálculos provisionales efectuados por el ajustador, el armador reclama a los consignatarios de las mercaderías o a sus aseguradoras, el afianzamiento de los montos de cada una de las contribuciones exigibles, cuyo otorgamiento es indispensable para liberar la carga y proceder a su entrega una vez se arribe al puerto de destino. En efecto, dentro de las facultades del transportista, según el artículo 1033 del Código de Comercio, se encuentra la de retener las mercancías e incluso de solicitar su venta en subasta, puesto que la avería gruesa, según los artículos 1556 y 1566 del mismo Código, constituye un privilegio marítimo que genera derecho de retención sobre los bienes de los participantes en la expedición náutica, a quienes se les impone efectuar el depósito u ofrecer una garantía.

\section{DISTINCIÓN ENTRE EL RÉGIMEN DE RESPONSABILIDAD CONTRACTUAL Y EL RÉGIMEN JURÍDICO DE LA AVERÍA GRUESA COMO UN INCIDENTE MARÍTIMO MAYOR}

Excepción hecha respecto de la aplicación del principio iura novit curia en la instancia de Casación (Bonett Ortiz, 2015), el tema de la determinación del fundamento jurídico de la acción tiene consecuencias directas para el éxito o el fracaso de las pretensiones de las partes en litigio, como lo demuestra la decisión de la Corte Suprema de Colombia en este caso. La calificación jurídica de los hechos, que a la postre es lo que define el fundamento sobre el cual se estructuran las pretensiones, fue uno de los temas principales 
tratados por la Sala Civil en la Sentencia comentada de 5 de abril de 2021. Así, los efectos serán diferentes si lo que busca el demandante es declarar la responsabilidad civil del transportador, o la repetición en contra de la persona culpable del siniestro de avería gruesa. Para diferenciar ambas instituciones jurídicas la Corte utiliza dos criterios. De un lado, menciona un criterio relativo al evento desencadenante de la obligación civil (1). De otro lado, utiliza un criterio relativo al tipo de expensas que configura la obligación contributiva en la avería gruesa (2).

\section{El Evento Desencadenante de la Obligación Contributiva en la Averia Gruesa}

La Corte procede a hacer una distinción entre los fundamentos propios a la responsabilidad contractual y los fundamentos propios a la obligación contributiva en la avería gruesa. Considera $\$ 3.5 .2 .4$. que la responsabilidad contractual del transportador proviene de la inejecución, ejecución defectuosa o realización tardía de sus obligaciones convencionales. Por ello, si el porteador ejecutó su obligación de conducir las mercancías desde los puertos de origen hasta los puertos de destino, en el estado en el que las recibió y dentro del plazo pactado, gestión con la que el acreedor obtuvo el resultado inmerso en el contrato y satisfizo el propósito querido con la operación de traslado, se considera que el acuerdo de voluntades se cumplió a cabalidad, de forma que no surge deber resarcitorio para el armador.

En cambio, la declaración de la avería gruesa por razón de los gastos extraordinarios que se debieron realizar para atender el costo de las tareas de salvamento no es constitutiva de incumplimiento del contrato de transporte marítimo, sino producto del siniestro marítimo. De esta forma, concluye la Corte \$3.5.2.4. que aún si el hecho dañoso fue el resultado de una conducta negligente del capitán, la obligación de contribuir a la avería no emanaría de esa culpa, sino de la relación que se conforma entre los interesados en la embarcación frente a los riesgos a los que están sometidos en la aventura náutica.

En este proceso quedó claro que la calificación jurídica del fundamento de la demanda no juega necesariamente a favor del demandante, como se esperaría de la aplicación del principio iura novit curia. Para la Sala §3.5.2.3.2. aunque el recurrente hubiera querido presentar su reclamo como de naturaleza indemnizatoria, las contribuciones a la avería gruesa no tuvieron su fundamento en las obligaciones resarcitorias que surgen de un obrar negligente del capitán. Por el contrario, surgieron de la relación "si se quiere solidaria" en palabras de la Corte, que el derecho marítimo impone a los participantes de la aventura marítima cuando fue necesario salvar la embarcación de los peligros de la travesía náutica. Reitera entonces la Sala §3.5.2.3.2. que las acciones que surgen de la avería gruesa tienen un fundamento legal autónomo, esto es el artículo 1520 del Estatuto de Comercio, que debe aplicarse cuando el origen del siniestro no fue el desconocimiento de un deber contractual, sino un encallamiento en el puerto de Barranquilla que constituyó un siniestro marítimo mayor.

Esta posición de la Corte colombiana se conmueve con lo establecido en otras jurisdicciones de países industrializados. La literatura indica que, en el caso de Francia, 
la declaración de avería gruesa no tiene efectos frente a la demanda que busca la rescisión del contrato de transporte, que, salvo en caso de desaparición de la mercancía, se extinguirá en el momento de su entrega (Bernie, 2009). Es de esta manera que la Cour de cassation decidió que la acción de la avería gruesa, que tiene por objeto el reparto de los gastos y daños causados por las medidas de salvamento decididas en interés común, es independiente del procedimiento judicial concomitante para determinar la responsabilidad de los participantes en la operación de transporte marítimo?.

\section{E1 tipo de expensas que configuran la obligación contributiva en la Averia Gruesa}

La Corte no solo utilizó el criterio relativo al origen del siniestro, como viene de plantearse, sino también el que se refiere al tipo de gasto que debió efectuarse luego de declarado el siniestro. En efecto, para la Sala §3.4.4., la de asunción de valores adicionales al flete, esto es, los montos relativos al pago de las labores de socorro y asistencia, no corresponde a una de las indemnizaciones que surgen del desconocimiento de las obligaciones del transportador: "el apoyo económico destinado al salvataje en beneficio de las cargas transportadas" no tiene un carácter resarcitorio de origen contractual. Por ello, contrario a lo que afirmaba el recurrente en la Sentencia de 5 de abril de 2021 (§3.5.2.1.3.) los artículos 1008 a 1035 del Código de Comercio se refieren únicamente a la reparación de los daños causados a los bienes, elementos o mercaderías transportados, sin que en estos se incluyan los gastos o expensas que deben realizarse de forma urgente para evitar los riesgos mayores de la aventura marítima.

Recuerda además la Corte §3.7.1.4. que el artículo 1501 del Código de Comercio exige del capitán el emplear todos los medios a su alcance para salvar la nave, cuando en el curso del viaje ocurran eventos que la pongan en peligro, de forma que está autorizado para contratar el salvamento, con autorización del armador. Así, según el artículo 1545 de este Código, todo acto de asistencia o de salvamento cuyo resultado haya sido útil, dará lugar a una remuneración equitativa. El mismo artículo define la asistencia como el auxilio que una nave le preste a otra que se encuentre en peligro de pérdida, y como salvamento, la ayuda prestada una vez ocurrido el siniestro. La doctrina menciona que dentro de los gastos propios a la institución de la avería gruesa se encuentra la remuneración por el auxilio prestado, el reembolso de los gastos incurridos en la operación de salvamento y el pago de los servicios excepcionales prestados por el remolcador según el caso (MonTAS, 2017).

Por ello, para la Sala §3.7.1.5., este tipo de costos se les admite dentro de la categoría de avería-gasto, tratándose de estipendios extraordinarios necesarios para conjurar un peligro real y actual que amenaza a la totalidad de la comunidad navegante ${ }^{10}$. Concluye la Corte \$3.5.2.1.3. que mientras el artículo 1030 del Código de Comercio se refiere al deterioro físico sufrido por la mercancía transportada, las reglas $1514 \mathrm{y}$ 1516 se refieren a las pérdidas y los gastos necesarios para solventar el navío. Como

\footnotetext{
9 Ch. com. 1 décembre 2009 n. 08-14203 et 08-14585 citado (Bernie, 2009).

10 Los gastos que son tenidos en cuenta dentro de este rubro dependen de los instrumentos internacionales aplicables según el momento en que tuvo lugar el siniestro.
} 
elementos de este tipo de gastos la Corte reconoce $\$ 3.7 .1 .5$. aquellos mencionados en el Decreto-Ley 2324 de 1984, además de otros instrumentos internacionales ${ }^{11}$, en consonancia con el artículo 1513 del Código de Comercio, que para definirlos recurre a la ley, los tratados, convenios y a la costumbre internacional o nacional.

Al respecto, la dogmática jurídica en derecho francés realiza igualmente una distinción entre la avería-costes y avería-perjuicios. Mientras que el primero se refieren a los gastos incurridos por el capitán, los gastos de salvamento y remolque, salarios y gastos de mantenimiento de la tripulación correspondiente al período de desvío y hasta el retorno al puerto de salida), los segundos se refieren a los daños sufridos por los intereses embarcados como consecuencia de la decisión del capitán (lanzamiento de mercancías al mar, disminución de las mercancías) (MoNTAS, 2017).

\section{LA ACCIÓN SUBROGATORIA DEL ASEGURADOR EN LA AVERÍA GRUESA}

En el ámbito de los seguros, es común que los contratos cubriendo los riesgos sobre las mercancías otorguen cobertura por los daños materiales cuya causa proviene de cualquier riesgo del mar o incluso, según el caso, por otros acontecimientos de fuerza mayor. También se incluyen en la garantía los gastos ocasionados para limitar las pérdidas o para preservar el objeto asegurado de los daños materiales (MonTAS, 2017). Es bien sabido que el asegurado no debe acumular la prestación debida por el asegurador con la indemnización debida por el responsable del daño (SÁNCHEZGARCÍA, 2018), regla aceptada en aplicación del principio indemnizatorio (KuLLMANN, 2020). La aplicación de este principio en el derecho de seguros ha sido convalidada por la jurisprudencia ${ }^{12}$. Por esta razón, una vez que el asegurador ha pagado la indemnización del seguro, éste "hereda" el derecho que tiene el asegurado contra la persona responsable. En cuanto al asegurado, una vez que ha sido indemnizado, ya no tiene legitimación para actuar en contra la persona responsable (Jaramillo, 2011), excepto por la parte del siniestro que no fue indemnizada por el asegurador. Aunque en derecho sustantivo el límite de la acción del asegurador es el principio indemnizatorio, siguiendo el análisis de la Corte colombiana, nos ocuparemos del marco temporal en el cual dicha acción debe ser ejercida por el asegurador subrogado (B). Antes de referirnos a este respecto, recordaremos algunos elementos esenciales de la acción subrogatoria del asegurador (A). Por ultimo y a modo de conclusión nos ocuparemos de elucidar cuál es la importancia actual del instituto de la Avería Gruesa como un modo singular de asunción de riesgos (C).

\section{A. La Acción del Asegurador Subrogado}

Se considera que en los seguros de transporte el asegurador que ha pagado la indemnización del seguro adquiere, hasta el importe de su pago, todos los derechos del

\footnotetext{
11 La Corte menciona la Resolución MSC.255 (84) aprobada el 16 de mayo de 2008 por la Organización Marítima Internacional.

12 Cass. 1re civ., 30 oct. 1995, n. 93-14.147.
} 
asegurado derivados del daño que dio lugar a la garantía (LeguaY, 2019). Aunque el derecho marítimo y el derecho de seguros marítimos son en general de carácter especial y autónomo, a falta de una disposición legal o jurisprudencial reglando la cuestión ${ }^{13}$, la noción de la subrogación del asegurador sigue las reglas clásicas de derecho de seguros terrestres. Esta acción tiene un fundamento jurídico que se encuentra en la dogmática y en la jurisprudencia (1), pero debe también cumplir, para ser admisible, unas condiciones que le son propias (2).

\section{El Fundamento Jurídico de la Acción del Asegurador Subrogado - El principio de identidad}

La subrogación es actualmente una institución esencial del derecho de seguros contemporáneo y representa un importante número de acciones judiciales. Un primer fundamento de la subrogación se encuentra en el principio de derecho civil según el cual la persona que, teniendo un interés legítimo, paga y extingue una deuda, libera a la persona sobre la cual debe recaer la carga final de la deuda. (Kullmann, 2020). En derecho colombiano la subrogación está consagrada en los artículos 1096 y 1670 del Código de Comercio, y en derecho francés en el artículo L. 121-12 del Code des assurances.

La Corte Suprema de Justicia de Colombia ha reconocido el origen civil de la regla subyacente a la institución de la subrogación. En la Sentencia de 5 de abril de 2021, §3.5.2.5. concluyó la Sala que, de manera análoga al derecho civil, por efecto del pago, al acreedor subrogado se le transmite inmodificada la deuda de la cual era titular el subrogante, según se establece en el artículo 1666 del Código Civil. Por ello, señala la Corte, una vez que la compañía de seguros realiza el pago de la indemnización, ipso iure sustituye al asegurado en el crédito que tenía contra el responsable de su pérdida patrimonial, en las mismas condiciones que ostentó en su posición como perjudicado directo.

La naturaleza del derecho ejercido por el asegurador se encuentra en la relación subyacente que le dio origen al deber indemnizatorio. El derecho así adquirido, como lo ha explicado la jurisprudencia "no sufre ninguna mella o alteración por migrar del asegurado a la entidad aseguradora" ${ }^{\prime \prime}$. La Corte colombiana instituye así un principio de identidad que rige la acción del asegurador. Por ello es que los responsables del siniestro podrán oponer al asegurador las mismas excepciones que pudieren hacer valer contra el damnificado ${ }^{15}$, puesto que la subrogación, aclaró la Corte, traspasa al nuevo acreedor todos los derechos, acciones y privilegios, prendas e hipotecas del antiguo, así contra el deudor principal como contra terceros, obligados solidaria y subsidiariamente a la deuda ${ }^{16}$.

En la Sentencia comentada de 5 de abril de 2021, \$3.5.2.5.1. nuestra Corte se refirió nuevamente a este principio de identidad, reconociendo que éste es predicable del derecho subrogado, que es únicamente el que el asegurado podía ejercer contra quien dio lugar al

\footnotetext{
13 En derecho francés el articulo L. 172-29 du Code des assurances establece que el derecho de subrogación es aplicable a todos los aseguradores sin distinción del ramo.

14 CSJ, SC 18 may. 2005, rad. 0832-01.

15 Ibidem.

${ }^{16}$ CSJ SC17494, 14 ene. 2015, rad. 00144.
} 
hecho amparado en la póliza. La identidad se hace entonces extensiva a la acción a través de la cual se ejercitará el instrumento judicial cuya titularidad se radica en el asegurador por efecto de la subrogación y que es el mismo que tenía a su alcance el asegurado.

Se considera que el asegurador de daños puede subrogarse en los derechos de su asegurado, ya que su prestación tiene un carácter indemnizatorio, lo cual no ocurre en otro tipo de seguros donde el asegurador se compromete a otorgar una única suma global (LEGUAY, 2019). El monto que puede reclamar el asegurador en ejercicio de la acción subrogatoria se encuentra demarcado por lo que éste mismo ha pagado a su asegurado. Así, tratándose del ramo de seguros transporte, cuyas principales garantías en los riesgos de bienes en el área marítima son el seguro de casco y maquinaria y el seguro de carga, el monto máximo a reclamar por el asegurador corresponde al valor de la cosa asegurada al momento de siniestro, pues se trata de seguros patrimoniales (KuLLMANN, 2020), es decir, como ha sido mencionado por la jurisprudencia, la reclamación del asegurador será circunscrita a lo que puede ser pagado como indemnidad en el contrato de seguro de transporte ${ }^{17}$.

El fundamento económico de la institución es entonces la prestación pagada por el asegurador, de manera que se considera que cuando éste no estaba obligado a amparar el siniestro según las cláusulas contractuales, al hacerlo, no está legitimado a ejercer una acción subrogatoria en contra el responsable del siniestro (DELEBECQUE, 2014). Ello no impide que el asegurador quede subrogado cuando una parte del monto pagado correspondió efectivamente a una de las garantías suscritas por el tomador ${ }^{18}$. Este es el mismo razonamiento que conlleva a afirmar que si el asegurador paga la indemnidad incluyendo el deducible del seguro, ello no le impide quedar subrogado por la fracción que correspondió a la ejecución del contrato de seguro (DELEBECQUE, 2014).

La jurisprudencia francesa ha así interpretado que en el caso en el cual la aseguradora realizó el pago como un "gesto comercial", es decir sin que se haya tratado de la ejecución de una garantía de seguro, no puede ejercer una acción subrogatoria en contra del accipiens. Por ello, tratándose de un gesto comercial, no se considera que éste le otorgue un derecho al asegurador de obtener una restitución respecto del responsable ${ }^{19}$. Otro es el caso cuando el asegurador pagó por error, pues en tal caso una acción le es otorgada. En efecto, la jurisprudencia ha considerado que, aunque no se subrogó en los derechos del acreedor, el asegurador que indemnizó por error el siniestro tiene una acción en contra del responsable en aplicación del principio general del derecho según el cual nadie puede enriquecerse injustamente a costa de otra persona ${ }^{20}$.

\section{Condiciones de la Acción del Asegurador Subrogado}

Es frecuente que los transportistas y sus aseguradoras soliciten la inadmisibilidad de la demanda y el rechazo de las pretensiones de la acción subrogatoria de las compañías

17 Cass. 1re civ., 7 mai 2002, n. 99-11.937.

18 Cass. 2e civ., 21 févr. 2008, n. 07-10.401

19 CA Amiens, 11 sept. 2014, no 12/04961, Nikon France et a. c/ TDL citada por Delebecque, 2014.

${ }^{20}$ Cass. 1ère civ. 4 avr. 2001, Bull. civ. I, no 105 ; Cass. 2ème civ. 10 juill. 2008, DMF 2008, 913, obs. MM. Dablemont et Turgné citada por (Delebecque, 2014). 
de seguros que otorgaron una prestación a los propietarios de las mercancías en aplicación del contrato de seguro. El tema es objeto de debate judicial puesto que la subrogación presupone que se tengan derechos a transmitir por el asegurado, de allí que el problema sea generalmente analizado bajo el espectro procesal de la legitimación del actor (TILCHE, 2013).

Dos condiciones son necesarias para que el asegurador pueda beneficiar de la subrogación: de un lado, debe probar que efectivamente ha pagado la indemnización debida, y de otro lado, que dicho pago lo ha hecho de acuerdo con las cláusulas de la póliza. Por ello la aseguradora debe demostrar la transferencia o todo elemento relativo al pago. También la materialidad del siniestro debe compararse con las condiciones del seguro, lo cual exige entonces una labor interpretativa judicial en la determinación de las modalidades, condiciones y efectos de la garantía de seguro de la causa (DelebeCQue, 2014). La jurisprudencia en derecho marítimo se ha ocupado de la cuestión determinando que la compañía del seguro de carga no está legitimada a actuar en subrogación contra el transportista, en ausencia de la prueba de la póliza de seguro y de la realidad del pago de la indemnización ${ }^{21}$.

Frente al momento en el cual debe ser ejecutado el pago, la jurisprudencia ha considerado que, para que la demanda sea admitida, no es necesario que el asegurador haya cancelado su prestación económica, puesto que ésta puede realizarse hasta antes de la sentencia ${ }^{22}$. La doctrina considera que esta solución es muy importante si se tienen en cuenta los cortos términos de prescripción propios del derecho de trasporte (Kullmann, 2020).

Nuestra Corte Suprema ha mencionado \$3.5.2.5.4. (Sentencia SC1043-2021, Sala Civil, 5 abril 2021 MP. Luis Armando Tolosa Villabona, 2021) que efectivamente en el ordenamiento jurídico colombiano el pago de la prestación originada en el convenio de seguro determina la legitimación por activa de las aseguradoras, siendo el valor pagado la "medida del derecho" que pueden reclamar por esta vía. Reconoció que ese derecho está inmerso en la relación jurídica subyacente, de forma que, en el caso fallado por la Sala en dicha ocasión, el derecho del asegurador no nació del incumplimiento del porteador en sus obligaciones, sino del pago efectuado debido a la avería gruesa.

\section{B. LIMITES TEMPORALES DE LA ACCIÓN SUBROGATORIA DEL ASEGURADOR EN LA AVERÍA GRUESA}

En la Sentencia de 5 de abril de 2021 la Corte Suprema determinó en un primer lugar cuál es el régimen propio a la acción incoada por las aseguradoras (1) para luego concluir cuál es el régimen de prescripción que le es aplicable a dicha acción (2).

\footnotetext{
${ }^{21}$ Cour d'appel d'aix-en-provence (2ème ch.) - 15 mai 2014, Navire Westermuhlen n. 12.12130 citada por (Delebecque, 2014).

22 Cass. 3e civ., 29 mars 2000, n. 98-19.505.
} 


\section{La determinación del Régimen de la Acción Subrogatoria del Asegurador}

Para la determinación del régimen prescriptivo que debía aplicarse en el caso fallado en la Sentencia de 5 de abril de 2021, la Corte debió identificar cuál era la clase de acción judicial que promovían las aseguradoras demandantes con el fin de recuperar el importe de las expensas asumidas luego de declararse la avería gruesa.

Para responder a esta pregunta la Sala Civil §3.5.2. procedió a una subsunción normativa de los hechos establecidos en el proceso. Se trato de : i) La motonave que movilizaba mercaderías de diversos importadores encalló a su ingreso al puerto de Barranquilla el día 18 de noviembre de 2010; ii) Por lo ocurrido, el capitán de la embarcación declaró la avería gruesa y contrató las labores de salvamento tendientes a reflotar el navío; iii) Para la definición de los aportes correspondientes, fue llamada una firma especializada en ajustes de ese tipo de sucesos; iv) Se requirió a las compañías aseguradoras e importadora demandantes, el otorgamiento de una garantía pecuniaria; y v) Los comprometidos en la navegación consignaron en la cuenta de la firma ajustadora el equivalente al 15\% del valor de las cargas porteadas. De esta forma analizó el sentenciador que el conflicto se subsumía a la recuperación de las sumas pagadas luego de declarada la avería gruesa consagrada en el artículo 1516 del Código de Comercio colombiano.

A pesar de que en la Sentencia del Tribunal atacada se había realizado un análisis detallado de los hechos para determinar la calificación jurídica a otorgar a la reclamación, la censura consideró que el panorama fáctico descrito debía subsumirse en las disposiciones legales que rigen la responsabilidad del transportista. Sin embargo, la Corte Suprema rechazó el ataque a la Sentencia al confirmar \$3.4.4. que los montos asumidos por los importadores de la mercancía movilizada en el navío Stadt Bremen, no hacían parte de una contraprestación directa del contrato de transporte, ni de un exceso en el costo de éste. Para la Sala Civil, tales importes correspondieron a la figura de avería gruesa y despacha desfavorablemente la censura \$3.5.2.2. elevada respecto de la calificación jurídica de la reclamación presentada por las aseguradoras. La Corte excluye §3.5.2.5.3. pues que el Tribunal hubiera incurrido en yerro puesto que la controversia gravitó sobre el derecho de repetición de los valores pagados por concepto de las contribuciones a la avería gruesa, impuestas debido al interés en la seguridad de la navegación, de forma que la acción que los cargadores trasfirieron a las compañías aseguradoras emanó de ese instituto del derecho marítimo.

\section{E1 Régimen de Prescripción aplicable al Asegurador Subrogado}

Creyendo que el litigio estaba referido al incumplimiento de las prestaciones propias del contrato de transporte, la censura consideraba que la prescripción a aplicar era la bienal mencionada en el artículo 993 y el artículo 1554 del Código de Comercio. Para desechar tal alegación, la Corte aclaró que el término de prescripción al cual estaba sometida la causa judicial es el especial que consagra el artículo 1528 del Código de Comercio. Esta disposición se refiere a los litigios relacionados con la avería gruesa 
y bajo cuyo tenor las acciones derivadas de este instituto prescriben en el lapso de un año, contado a partir de la fecha en que termina el viaje.

De esta manera consideró la Corte que el Tribunal $\S 4$ no cercenó el derecho de las compañías aseguradoras de subrogarse en el recobro de los dineros que cancelaron al ajustador internacional Groninger \& Welke, ni desconoció su legitimación en la causa derivada del pago, que dio lugar a la subrogación prevista en el artículo 1096 del Código de Comercio. Por el contrario, se consideró que como el litigio no encuadraba dentro de la acción de responsabilidad contractual, pese a que así quisieron verlo los demandantes, fue evidente que la prescripción no se gobernaba en tal caso por la regla general del contrato de transporte, sino por la regla especial de la avería gruesa consagrada en el artículo 1528 del Estatuto Mercantil.

Sorprende que los reclamantes hubieran esperado una decisión diferente por la Corte Suprema frente a la cuestión de la calificación jurídica cuando, al menos en el caso en comento, no había dudas de que los gastos surgían directamente de la declaración de la avería gruesa. Nuestro Código de Comercio integra en efecto todas las hipótesis principales del transporte marítimo internacional y en ausencia de una laguna normativa, la demanda de casación parecía dirigida al fracaso. Frente a la decisión de fondo hay que mencionar que si bien ésta se conmueve con la doctrina internacional que señala que la subrogación del asegurador no existe en ausencia de vigencia del derecho subrogado (GARCía CAMPILlo, 2020), hay que mencionar que una decisión de la Corte de Casación de Francia consideró que aunque el pago del asegurador fue posterior al termino de prescripción, la acción subrogatoria de este pudo ser admitida ${ }^{23}$. Tal jurisprudencia, no ha sido por el momento confirmada por otras sentencias, pero puede conmoverse con el hecho de que se espera que la carga de la deuda pese sobre el patrimonio del responsable final, independiente de si, como en el caso juzgado por la Corte colombiana, unas limitaciones de orden procedimental volvieron inocua la acción subrogatoria de los aseguradores.

\section{IMPORTANCIA DE LA AVERÍA GRUESA COMO UN MODO SINGULAR DE ASUNCIÓN DE RIESGOS}

"La avería común nació de la navegación marítima y sólo desaparecerá con ella" anunciaban Rodière y Lureau en su Tratado de Derecho Marítimo de $1972^{24}$. Sin embargo, algunas voces de la doctrina critican la figura al considerar que ésta permite que los armadores no se hagan cargo de gastos que normalmente deberían ser de su responsabilidad. Otros consideran innecesaria la avería gruesa, ya que la contribución luego del siniestro es liquidada en la práctica por las aseguradoras, que podrían al fin de cuentas proceder a indemnizar a sus clientes sin esta práctica (CORBIER, 2016).

Sin embargo, la institución de la avería gruesa conserva una utilidad particular en la medida en que autoriza en la expedición marítima gastos muy costosos, que el capitán

${ }^{23}$ Cass. com., 26 janv. 2010, n. 08-21.778 citada por (Garcia CAmPillo, 2020).
${ }^{24}$ Op. cit (Corbier, 2016). 
dudaría en realizar, si no supiera que serán reembolsados por todos los interesados (CORBIER, 2016). Mas importante aún es que ésta es una figura útil para prevenir o limitar los daños al medio ambiente. En efecto, en los instrumentos internacionales ${ }^{25}$ la indemnización especial a la que tiene derecho una persona que ha prestado asistencia a un buque en peligro que amenazaba con causar daños al medio ambiente, cubre todos los gastos efectuados, sin distinguir entre los realizados para preservar el buque y los realizados para preservar el medio ambiente (DELEBECQUE \& LÉVY, 2017). Al respecto, la Corte de Casación de Francia consideró ${ }^{26}$ que es permitido conceder el rembolso de todos los gastos incurridos en la operación de salvamiento realizados para evitar daños al medio ambiente, incluso en ausencia de un resultado útil evidente.

La avería gruesa es pues una institución singular pero útil en el enorme tráfico internacional actual donde altas sumas de dinero son en juego en cada aventura marítima. Algunos ajustes pueden hacerse evidentemente, como lo menciona la literatura, que indica que para evitar las liquidaciones abusivas que benefician a los armadores es necesario exigir una estricta relación de causalidad entre el sacrificio que da lugar a la liquidación y los daños o costes reclamados por la persona que ha sufrido el sacrificio. (CORBIER, 2016)

\section{BIBLIOGRAFÍA}

BERNIE, M. (2009). Avarie commune : procédure indépendante de l'avarie particulière, effet sur le contrat de transport et droit applicable aux frais de réexpédition des marchandises. Le Droit Maritime Français, 710(01/01/2010), 1-7.

Bonett Ortiz, S. A. (2015). El principio dispositivo de la casación. Revistas ICDP, 39(39). https://doi.org/10.32853/01232479.v39.n39.2013.38

CEPAL. (2019). Hacia la descontaminación del transporte marítimo del comercio internacional : metodología y estimación de las emisiones de CO 2. Boletín FAL (CEPAL), 373, 4-11. https://repositorio.cepal.org/handle/11362/45075

Corbier, I. (2006). Avaries communes. Répertoire de Droit International-Dalloz, 1-111.

Sentencia SC1043-2021, Sala Civil, 5 abril 2021 MP. Luis Armando Tolosa Villabona, (2021).

Delebecque, P. (2014). Subrogation légale et subrogation conventionnelle refusées. Le Droit Maritime Français, $N^{\circ} 762$, ler Octobre 2014, 1-5.

Garcia Campillo, L. (2020). Condition de la subrogation légale : un paiement obligé. In Le Lamy transport, tome 1 (pp. 992 - 10-11). Wolters Kluwer France.

JARAMillo, C. I. (2011). Delimitación temporal de la cobertura en el seguro de la responsabilidad civil -Adopción del sistema de aseguramiento comúnmente conocido como "claims made." Revista Ibero-Latinoamericana de Seguro, 20(35), 145-214.

Kullmann, J. (2020). Subrogation légale. In Le Lamy Assurances 2020 (Lamyline, p. 3150). Wolters Kluwer France soumis.

${ }^{25}$ Entre otros el Convenio Internacional de Londres sobre Salvamento Marítimo.

${ }^{26}$ Com. 14 juin 2016, n. 1428966. 
Landel, J. et al. (2014). Transport maritime, Dictionnaire Permanent Droit des assurances. Editions Législatives Dalloz, 39(2), 390-391.

LeguaY, V. (2019). Subrogation, Assurance (principes généraux), Dictionnaire permanente. Editions Législatives Dalloz.

Montas, A. (2017). Événements de mer - Avaries communes. Répertoire de Droit CommercialDalloz, 3.

SÁNCHEZ-GARCíA, M. (2018). Naturaleza del derecho de subrogación en el contrato de seguro y su relación con la cotitularidad del asegurado y asegurador frente al tercero responsable. Revista Ibero-Latinoamericana de Seguros, 27(49), 15-53. https://doi. org/10.11144/javeriana.ris49.ndsc

Tabares Cortés, F. (2017). La reforma del Código Civil Francés. Un proemio al cambio estructural de los principios de derecho privado del Código Napoleónico. Verba Luris, 38, 155. https://doi.org/10.18041/0121-3474/verbaiuris.38.1074 